\title{
Camilo José Cela nas correspondências: mediador cultural entre a península e o exílio
}

\author{
Camilo José Cela in the correspondences: a cultural mediator between peninsula and exile
}

\author{
Solange Munhoz \\ Centro de Educação Tecnológica Paula Souza - São Paulo
}

\begin{abstract}
Resumo: Por meio das cartas trocadas entre Camilo José Cela e os interlocutores Rafael Alberti, Max Aub e Américo Castro, examinamos a criação de redes de sociabilidade que possibilitaram a circulação de textos de escritores exilados na Espanha durante o franquismo. As correspondências evidenciam o alcance da censura institucionalizada e o papel de Cela como mediador nesse novo circuito cultural.

Palavras-chave: Correspondências; Camilo José Cela; Rafael Alberti; Max Aub; Américo Castro

Abstract: By means of the exchanged letters between Camilo José Cela and the interlocutors Rafael Alberti, Max Aub and Américo Castro, we examine the creation of sociability nets which enabled the circulation of exiled writers' texts in Spain during the Francoism. The correspondences evidence the reach of the institutionalized censure and Cela's role as mediator in this new cultural circuit.
\end{abstract}

$\diamond$

Keywords: Correspondences; Camilo José Cela; Rafael Alberti; Max Aub; Américo Castro

\section{De papel e pelo correio humano}

A regular publicação de livros de cartas por parte do mercado editorial espanhol nos últimos anos e a abertura de acervos de instituições públicas e privadas mostram evidências do ritmo intenso da troca epistolar e da importância dos temas abordados nas correspondências dos escritores espanhóis do século XX.

Apenas no que diz respeito à produção epistolar de Cela, a Fundación Pública Gallega Camilo José Cela custodia aproximadamente 95.000 cartas classificadas que foram trocadas com 13.000 interlocutores ${ }^{1}$. Uma pequena parte desse acervo pode ser conhecida por meio do livro Correspondencia con el exilio (2009) que reúne a correspondência que manteve com escritores exilados para, inicialmente, convencê-los a enviar colaborações originais para a revista Papeles de Son Armadans (PSA)². Nas cartas, lê-se sobre a gênese e o desenvolvimento dessa revista, bem como o empenho do diretor para construir um espaço de interlocução com os exilados e de divulgação de seus próprios textos. Por outro lado, podemos conhecer algumas consequências da Guerra Civil Espanhola (19361939) e da ditadura de Franco (1939-1975) na esfera cultural do país. Entre elas estão: os obstáculos que certos escritores encontram para voltar ao país, algumas experiências próprias do país de acolhida, a dificuldade de publicar na Espanha devido à institucionalização da censura e o estabelecimento de negociações e acordos para fazer circular ideias e originais.

A primeira edição do livro é 2009 , sendo que, ao longo de suas mais de 900 páginas, encontramos 839 documentos de diferentes missivistas, entre cartas, telegramas, postais e bilhetes. Na lista, constam os nomes de Rafael Alberti, María Zambrano, Américo Castro, Fernando Arrabal, Jorge Guillén, Max Aub, Emilio Prados, Luis Cernuda, Manuel Altolaguirre, León Felipe, Corpus Braga, Francisco Ayala e Ramón J. Sender. Com alguns dos escritores, Cela manteve uma longa correspondência (Américo Castro), com outros, trocou poucas cartas (León Felipe). Quanto à interlocução

\footnotetext{
1 Estes dados podem ser encontrados na página da fundação, cujo endereço eletrônico é: <https://fundacioncela.wordpress.com/colecciones/ epistolario/>. Acesso em: 10 mar. 2014.

2 Papeles de Son Armadans, Ínsula e Índice são revistas que circularam no final dos anos 50 que são reconhecidas como publicações que contribuíram para oxigenar a esfera cultural do período por, com maior ou menor frequência, abrirem espaço para os escritores exilados e pela qualidade dos textos e dos autores publicados. Projeto de Cela, Papeles de Son Armadans circulou entre abril de 1956 e março de 1979, totalizando 279 números em que colaboraram 1070 autores.
} 
com Max Aub, só estão publicadas as cartas escritas por Cela, por esse motivo, neste artigo, consideramos a correspondência cruzada que está arquivada nas fundações.

Entre as várias possibilidades de trabalho com esse material, interessa-nos estudar a criação de um território textual que funda um circuito do campo cultural na ditadura de Franco, um espaço de sociabilidade propício ao diálogo e à construção de diferentes relações de proximidade entre os escritores, em que Cela promove as obras dos autores do exílio tanto na revista quanto na Editora Alfaguara. Nesse sentido, identificamos como um dos aspectos de relevo para entender a construção da proximidade entre os interlocutores os resultados editoriais positivos que Cela alcançava ao submeter os textos ao controle da censura institucionalizada. Sendo assim, detemo-nos em referências que existem nas cartas à intervenção da censura - considerando suas variadas facetas, como a autocensura - quando se tratou da circulação das obras inéditas dos escritores exilados. Procuramos também identificar as estratégias desenvolvidas ou colocadas em prática por editor e por escritores para escapar à censura institucional.

Dada a impossibilidade de trabalhar com um material tão extenso e singular quanto o que está reunido no livro, decidimos restringir nossa análise a três correspondências, procurando abranger certas peculiaridades do todo. Assim, escolhemos as correspondências de Rafael Alberti, Américo Castro e Max Aub. Justificamos esta escolha pelo peso que tiveram como articuladores da produção cultural de artistas e intelectuais em algum momento, seja antes ou depois do exílio. A disposição dos escritores para participar ativamente do cenário cultural da Espanha pode ser vinculada à formação que receberam em um contexto que combinava "instabilidade social e estabilidade cultural", como esclarece Valeria De Marco ao discorrer sobre a identificação da intelectualidade espanhola com a II República (DE MARCO, 2008, p. 287).

Particularmente sobre as cartas de Max Aub, que estão ausentes no livro e continuam inéditas como conjunto, destaca-se o cuidado do autor com o arquivamento de sua correspondência ativa e passiva, a ponto de o número de documentos variar apenas ligeiramente quando se trata da comunicação entre ele e Cela. Dedicado escritor de cartas, Aub construiu um epistolário com mais de 10.000 documentos, depois de ter se refugiado no México em 1942.

\section{Redes de sociabilidade entre escritores e publicação de originais}

Tanto os textos de Alberti, Aub e Castro publicados em PSA - respectivamente, 7, 15 e 11 textos - quanto as cartas trocadas com Cela foram elaborados na mesma época. Inicialmente escritas para dar a conhecer a revista e pedir colaboração ou oferecê-la, dependendo de quem fizesse o primeiro contato, as cartas ressaltavam o aspecto mais prático e objetivo das necessidades editoriais. Ao longo da relação dialógica, ganharam nova dimensão à medida que passaram a incorporar posicionamentos sobre questões literárias, culturais, políticas e, conforme crescia a aproximação, pessoais e prosaicas. Todos esses temas cabem nas cartas, como é próprio do gênero epistolar, assim como cabe a aproximação de seu discurso com o literário. Tais movimentos assumem diferentes graus de relevância de acordo com a intenção dos correspondentes.

Valemo-nos do caráter documental associado à carta para entender e analisar a construção do diálogo entre os autores que estudamos, tentando respeitar sua complexidade e localizando-o em um contexto histórico mais amplo em que agentes culturais da península e do exílio se mobilizaram para estabelecer pontes de aproximação e cooperação intelectual. As correspondências dão notícia desse movimento e da configuração de redes de sociabilidade que se estabelecem de acordo com interesses comuns e se organizam em torno a certa sensibilidade cultural e afinidades entre os escritores, conforme nos explica Jean-François Sirinelli em seu ensaio sobre a definição do conceito de intelectual. Segundo ele, os intelectuais se reúnem "em torno de uma sensibilidade ideológica ou cultural comum e de afinidades mais difusas, mas igualmente determinantes, que fundam uma vontade e um gosto de conviver" (SIRINELLI, 2003, p. 248). Acrescenta que revistas ${ }^{3}$, manifestos e abaixo-assinados são alguns dos espaços por meio dos quais poderíamos observar a sociabilidade, embora variem de acordo com a época e os grupos e subgrupos de intelectuais envolvidos:

As estruturas de sociabilidade variam, naturalmente, com as épocas e os subgrupos intelectuais estudados. Assim, se os 'salões', na fronteira entre os dois séculos, constituíam uma casa importante no jogo de ludo dos intelectuais, com suas musas da sociabilidade, eles não figuram mais entre os elementos decisivos que hoje quadriculam e subtendem intelectualidade (SIRINELLI, 2003, p. 249).

Entendemos que um possível desdobramento do conceito, ao considerar Sirinelli as particularidades do momento histórico e de cada grupo em formação, compreende a correspondência entre autores espanhóis do século XX como espaços de sociabilidade, dada a

\footnotetext{
3 Sirinelli (2003, p. 249) entende que a revista "é antes de tudo um lugar de fermentação intelectual e de relação afetiva, ao mesmo tempo viveiro e espaço de sociabilidade, e pode ser, entre outras abordagens, estudada nesta dupla dimensão".
} 
necessidade de romper a dispersão geográfica entre os interlocutores, bem como a profusão de material e a qualidade do material. Além de disso, a maleabilidade do gênero epistolar e a competência dos autores em situação de comunicação permitem a divulgação de textos da esfera íntima em locais e contextos públicos - como leitura em encontros poéticos.

A rede de sociabilidade estabelecida pelas correspondências propiciava a circulação de textos inéditos que tinham a meta de serem publicados na Espanha, inicialmente em PSA, mas sem perder de vista a possibilidade de sua edição no formato de livro, desde que fossem aprovados pelo critério editorial e pelo controle dos órgãos censores. Ao examinar esse tema nas cartas, entendemos também como se estabelece e desenvolve a aproximação entre Cela e Alberti, Aub ou Castro. Sendo assim, torna-se necessário aprofundar o estudo, recuperando os debates e, se possível, as ações que permitiram que os textos passassem pelo controle da censura institucionalizada, apesar do pouco espaço que Cela dá às etapas de sua negociação com as esferas oficiais. Ação curiosa para salvar um texto da censura é narrada não por Cela, e sim por seu filho, Camilo José Cela Conde. Trata-se da história da publicação por meio de PSA do livro escrito por Cela e ilustrado por Picasso, Gavilla de fábulas sin amor, considerado por Alberti como admirável ${ }^{4}$. De acordo com Cela Conde:

[Cela] Se fue hasta El Escorial a ver a Saturnino Alvarez Turienzo, un sacerdote y teólogo de gran prestigio, llevándole el libro para que emitiera su capacitada opinión. Fue favorable. Alvarez Turienzo no encontró en él nada que fuera de especial gravedad para la Iglesia Católica, ni para la salvación de sus fieles [...]. Con el nihil obstat de un hombre de la Iglesia como Alvarez Turienzo, la censura, aunque a regañadientes, no tuvo más remedio que dejar pasar el libro. [...] Una vez impreso el libro, el ministro Arias Salgado montó en cólera. Se confirmaron todos los malos augurios, todas las sospechas. Los textos eran blasfemos, dijeran lo que dijesen los teólogos. Y había que añadir los dibujos, claramente pornográficos en la opinión de tan notable autoridad en materia de escándalos. Así que se cernió sobre el libro la orden de prohibición y la amenaza del secuestro (CELA CONDE, 1989, p. 138-139).

Alberti conhece o livro de Cela e Picasso porque, conforme complementa Cela Conde, poucos meses depois da ordem de proibição, aconteceu a reforma de gabinete

\footnotetext{
4 Diz Alberti, escrevendo desde seu exílio em Roma: “QQué estupendo su libro [Gavilla de fábulas sin amor] con los colores de Picasso! Gran suerte la suya. Yo quise siempre tener alguna obra mía ilustrada por él. Pero desde Buenos Aires no era posible. A comienzos de otoño iré a verlo. Ahora no estoy tan lejos como antes" (CELA, 2009, p. 119-120).
}

por meio da qual se destituiu Gabriel Arias Salgado e se nomeou Manuel Fraga Iribarne como ministro da pasta de Informação e Turismo. Fraga Iribarne revogou o veto que pesava sobre as obras La colmena e Gavilla de fábulas sin amor. Em um de seus últimos trabalhos, Fernando Larraz revela que a proximidade entre Fraga Iribarne e Cela teria originado um acordo por meio do qual o escritor havia conseguido a promessa do ministro de isentar PSA dos trâmites censórios em troca de cooperação que poderia estender-se às tarefas de "espionaje y delación que Cela desempeñó en el encuentro 'Realismo y Realidad en la literatura contemporánea', en octubre de 1963” (LARRAZ, 2014, p. 148). Não há registro desse tema nas cartas, talvez porque, entre outros motivos, os interlocutores parecem se propor a um diálogo que se volta para a construção de algo novo, apesar das diferenças que os caracteriza, como demonstra os esforços para resolver certos enfrentamentos.

Nas correspondências, destaca-se a imagem de Cela como editor comprometido com seu grupo de artistas editados que naturaliza as gestões para salvar um texto integralmente e prefere deter-se em tranquilizar seus interlocutores; por outro, à medida que vai encontrando abertura na política do Estado para a censura, preocupa-se menos com as orientações preventivas e mais em estimular os escritores a produzirem obras, cuja única medida de controle fosse dada pela qualidade artística - textos, obras de artes plásticas, como as ilustrações e linoleogravuras preparadas por Alberti, e outros - para que as desse a conhecer por meio de PSA ou de outra instituição cultural sob sua responsabilidade.

Nesse sentido, é esclarecedor o diálogo que tem com Alberti sobre a censura ao pedir texto para ser publicado pela editora Alfaguara, fundada em 1964 pelo construtor Jesús Huarte e dirigida por Camilo José Cela e seus irmãos Juan Carlos Cela Trulock e Jorge Cela Trulock. O poeta esclarece que está escrevendo alguns textos sobre Roma e acrescenta: "Ahí, en España, funciona la censura y en esos poemas romanos no me muerdo la lengua. Si una vez terminado se lo propusiera a usted, ya sé que tendría que mutilarlo y eso le quitaría toda su gracia y realidad" (CELA, 2009, p. 121). A resposta de Cela valoriza seu conhecimento sobre a censura ao insinuar que existe uma maneira "oportuna e inteligente" para sobrepujá-la, ainda que não indique qual é:

Mil gracias por ese posible -y futuro- libro inédito romano. Es cierto que en España hay censura pero no lo es menos que, con una lidia oportuna e inteligente, puede ser derrotada. En todo supuesto pienso que la batalla debe plantearse y, en su caso, usando la artillería gruesa. Con el no ya estamos, y el sí, a veces, se produce (CELA, 2009, p. 121). 
Aproximadamente uma década antes, caracterizava seu trabalho com a censura de maneira similar a Américo Castro. Quando se convence de que valia a pena publicar em PSA, Castro envia duas colaborações no ano de 1957 e se compromete a enviar outra, se as primeiras fossem publicadas, acreditando que o maior empecilho estava na história associada ao seu nome e não nas ideias específicas contidas nas colaborações. Na resposta de Cela à preocupação de Castro, existem mostras de algumas de suas estratégias de intervenção - ampliando-se a já citada sobre sua obra em parceria com Picasso, ou seja, a de pedir a aprovação de uma figura de relevo, naquele caso, religiosa - como a de apresentar os textos separadamente, além de justificar seus êxitos como editor de escritores pouco apreciados pelo regime com base em um exercício de paciência. Outro ponto que aborda é o da definição de um modelo de sustentação desses nomes na revista graças aos seus próprios editoriais, apesar do risco que corria de ser ele próprio censurado:

Para no alarmar, no envío -en esta ocasión- sino uno: el de '[Santiago y] los Dioscuros'. Para este número he escrito un editorial que titulo 'El viejo profesor'; en él no le cito pero sí, claro es, le aludo desde el principio hasta el fin. Veremos también si navega con vientos propicios. Ojalá todo marche y usted -'con tiempo y en forma'- me escriba sobre La Celestina. Soy paciente y cabezón - dos virtudes quizás de precario pero que suelen faltar a los españoles- y no suelo entregarme con facilidad. Lo digo a cuenta de la lidia de sus papeles con nuestra siempre benemérita y tutelar censura (CELA, 2009, 171-172).

Outro motivo de importância do tema da censura está em trazer à luz informações encontradas na esfera íntima da troca epistolar sobre a perseguição à produção cultural escrita - que, por sinal, atravessou todo o período de ditadura franquista - que poderia incidir sobre o livro sob a forma de repressão ao material em circulação para sua desaparição definitiva ou temporária ou sob a forma de censura ao texto a ser editado e divulgado. Decorrem daí duas consequências principais: a de impedir o retorno do texto reprimido ou, ainda, a de instalar um tipo específico de texto autorizado, criando um vazio cultural para que o discurso do Estado pudesse se instalar e preenchê-lo, conforme explica José Andrés de Blas (2008). Para estabelecer a diferença entre definições interrelacionadas (isto é, entre repressão e censura), Andrés de Blas apoia-se nos estudos pioneiros de Manuel Abellán, discutindo alguns conceitos, dando-lhes nova leitura ou alinhando-os para torná-los operacionais. Embora estejamos considerando conceitos articulados com base no estudo da perseguição ao livro e à produção literária, pensamos que, dada a funcionalidade deles, por alguns motivos podemos estendê-los às questões abordadas nas cartas relativas aos textos literários ou críticos, mesmo quando está em primeiro plano sua publicação na revista PSA.

O primeiro desses motivos considera que tanto os livros quanto as revistas e outros periódicos eram regidos pelos mesmos parâmetros de vigilância de censura prévia e/ou definitiva. O segundo, refere-se ao fato de a execução do projeto de PSA ter-se ampliado conforme certas especificidades ao longo de sua existência, alcançando a publicação de livros em diferentes coleções. A título de exemplo, as 50 separatas numeradas dos artigos publicados presenteadas ao autor poderiam ser editadas em maior número em situações especiais. Uma delas surgiu a pedido de Américo Castro que, como uma espécie de comemoração por publicar na Espanha depois de 20 anos de ausência, encomendou a edição de 1000 separatas de sua primeira colaboração na revista: "Si, en contra de lo que espero, permitieran lo de 'los Dioscuros', tendría que hacer mil sobretiros a mi costa, naturalmente" (CELA, 2009, p. 174). No começo da década de 70, a revista publicou Pequeña y vieja historia marroquí, de Max Aub, por meio da coleção Azanca, dedicada ao ensaio e à narrativa, como aparece no anúncio do projeto feito por Camilo José Cela Conde. Merece destaque o bom humor com que "Camilo José Cela, hijo" - como assina a carta - lembra a fragilidade e a instabilidade do projeto, apesar da perspectiva de reunir material de qualidade, por depender do beneplácito de instituições que estavam fora do controle dos criadores - "hasta que nos la cierren" (CELA CONDE, Carta de 15/02/70).

Retomando as considerações de Andrés de Blas, encontramos ainda que a delimitação dos conceitos permite compreender os desdobramentos da censura que, a partir de seu lugar institucionalizado e respaldado por ações administrativas, projetava seu discurso em outros agentes sociais. Próprios de seus desdobramentos são a autocensura e "outras censuras" - que o autor considera como "censura social" ou "segunda censura" - bem como os efeitos que alcançam o leitor (ANDRÉS DE BLAS, 1999, p.281-301). Tais efeitos não são suficientemente discutidos ao longo do corpus para que possamos tecer considerações, enquanto os outros desdobramentos aparecem com mais ou menos evidência de acordo com cada conjunto de cartas.

Além da censura institucional e da autocensura, entendendo-a como as providências adotadas pelo autor para antecipar-se à exclusão de seu texto de certo espaço editorial, às possíveis supressões ou às alterações censórias administrativas, interessa-nos identificar nas cartas referências a duas outras censuras. A primeira, volta-se para certa característica do mercado editorial que, respondendo também às imposições da censura 
institucional, deveria publicar alguns textos em edições de luxo ou em pequenas tiradas. A segunda, diz respeito ao papel do editor ao realizar a seleção de textos e propor modificações prévias à sua apresentação oficial para aumentar as chances de publicação, levando-o a atuar, se não como um censor extraoficial, ao menos como um especialista em estratégias censórias, afinal, dada a submissão da imprensa e das editoras à política de Estado, supunha-se que o editor "realizase una censura previa a la oficial y que tuviese buen cuidado de no presentar ningún texto que levantase las sospechas del censor" (ANDRÉS DE BLAS, 1999, p. 290).

Começamos pelo único fracasso editorial de Cela, nos limites do nosso corpus, que foi o de não publicar o texto de Max Aub Homenaje a los que nos han seguido. $\mathrm{Na}$ carta em que informa a derrota, Cela, em uma das poucas vezes, estende-se no lamento sobre as dificuldades que encontra ao realizar seu trabalho e pede que Aub o facilite, enviando texto menos comprometedor. A dose de humor negro se completa com o pedido de que seja um conto desapaixonado que seria usado com o fim prático de escapar à censura:

Gracias por tu generoso Homenaje a los que nos han seguido, que -como me temía- se ahogó íntegramente en las 'procelosas ondas' de la censura. A veces, quienes andáis por ahí, os olvidáis de lo difícil (o, al menos, de lo incómodo y embarazoso) que resulta andar por aquí $[\ldots]$.

Mándame un cuento 'aséptico'. Quiero vencer la resistencia a tu nombre por parte de quienes pueden vetarlo. Ayúdame y no tomes actitudes románticas e ineficazmente juveniles (CELA, Carta de 13/04/1962).

A resistência sobre a qual comenta não é apenas com relação aos textos, e sim à presença de Aub na Espanha, cuja autorização para entrar no país foi sistematicamente solicitada desde 1953 e, igualmente, sistematicamente negada, até que consegue visitá-lo em 1969 com um visto de turista. Em uma das cartas a Cela, em que alude ao assunto, Aub dá mostra do seu desejo de voltar, tomado pela desesperança: “¿Me dejarán ir este año a Formentor? Supongo que tampoco. Y con las ganas que tengo..." (AUB, Carta de 19/01/1961).

A reclamação de Cela a Aub quanto ao trabalho com a censura contrasta com a proclamada confiança em seus méritos e habilidades. Por exemplo, quando o escritor exilado, ao convencer León Felipe a enviar poemas para PSA, cogita do risco de que o material seja interditado pela censura - "Ojalá no tengas dificultades con el Santo Sínodo" (AUB, Carta de 09/07/1958) - recebe a seguinte resposta otimista e até presunçosa: "Al Santo Sínodo me lo paso por el forro de las pelotas, también llamado escroto" (CELA, Carta de 20/07/1958).
A carta que inclui o comentário de Aub sobre sua Homenaje censurada dá notícias também sobre a morte de Emilio Prados, apenas um dia depois de ter ocorrido. Talvez pela dupla perda - a imposta pela censura e a imposta pela morte - o parágrafo final esteja imbuído do pessimismo causado pelo luto, que se dissemina e se reflete no lamento pelo risco de escrever à margem e pela ameaça de ser esquecido como autor por produzir textos que não encontrariam espaço no presente ou futuro - a ênfase está indicada na gradação dos marcadores espaciais "ahí" e "ningún sitio". Escreve Aub (Carta de 25/04/1962): "Gracias por tu carta del 13. Te mandaré un cuento 'aséptico'. Y cree que nunca he 'tomado actitudes', escribo lo que me sale, sin pensarlo mucho. Ahí queda eso. Lo malo, que no sirve, hoy para ahí. Y luego el tiempo pasa tan aprisa que ya no sirve para ningún sitio ni para nada".

No entanto, o abatimento de Aub não o impede de concluir que é mais útil para os seus propósitos enviar um conto que pudesse garantir a circulação de seu nome por meio de publicações em PSA. Ao discorrer sobre seu procedimento criativo, mostra a perfeita identificação entre temas e escritor. Por fim, resolveu o risco de que o texto não encontrasse o seu lugar, publicando-o no número de novembro do mesmo ano da Revista de la Universidad de México.

A análise de Homenaje a los que nos han seguido esclarece tanto o agradecimento de Cela no fragmento citado quanto o motivo de a censura institucional tê-lo proibido. Nele, Aub traça uma linha de continuidade literária em que os valores da cultura republicana, da qual é um dos representantes, podem ser identificados como herança de certo grupo de escritores da península, como é o caso dos nomes que cita, incluindo o de Cela ${ }^{5}$. Para eles, fazia a homenagem informada no título do artigo. No último parágrafo, considera o peso da censura sobre o trabalho dos escritores da península, embora entenda que nem mesmo ela é capaz de anular tal herança:

¿Cuántas veces me vi y veo en Aleixandre, en Dámaso, en Cela, en Otero, en los más jóvenes, cuando más jóvenes mejor, porque cada vez veo y nos y los veo más adelante? Lo poco que hacemos, para ellos. Aunque no podamos nada, para ellos. Lo que hicimos ¿si no para ellos, para quién? [...]

Con la censura a cuestas recorren largos caminos. Si tropiezan vuelven a la carga, con la carga en los hombros, como lo que son, antes que nada, hombres. Gracias a ellos, si no hemos de volver a pisar nuestra tierra, nos queda para siempre el consuelo de no haber vivido en vano (AUB, 1962, p. 17).

\footnotetext{
Javier Quiñones (2006, p. 285-297) amplia essas considerações, afirmando que Homenaje "se convierte así en una reivindicación de lo que podríamos llamar la cultura republicana o en sentido más amplio, la cultura de los años veinte y treinta que quedó truncada al final de la guerra civil en 1939".
} 
A leitura desse fragmento de Homenaje e do fragmento da carta de Aub citado anteriormente leva-nos a problematizar sua afirmação de que "nunca he "tomado actitudes" ao enviar o texto a Cela. Algo possível de acontecer, afinal era um intelectual experiente em várias áreas da produção cultural - escritor, tradutor, crítico de teatro, roteirista de cinema, entre outras áreas - e estava acostumado a experimentar e a provocar com as suas ideias e produções. O próprio Cela havia sido provocado por Aub. Em carta do ano de 1959, Aub propõe que o escritor galego preparasse o que fosse necessário para que uma escritora que não existia ganhasse o prêmio Nadal ou outro prêmio literário importante ${ }^{6}$. A escritora inventada remete-nos à mesma natureza de criação do personagempintor Jusep Torres Campalans. Cela rejeita a proposta de Aub, delimitando os contornos de sua relação profissional com o interlocutor, de seu lugar como editor e de seu projeto editorial:

No tengo en mi mano dar el Nadal ni ningún otro premio. Vivo, creo que por fortuna para mí, muy alejado de ese turbio mundo y tampoco tengo, esa es la verdad, ningún deseo de entrar en él. Te digo a cuenta de lo que me propones, que es gracioso, sin duda, pero para mí no viable. Mercedes Raventós suena muy a Premio Nadal. Si llegas a presentarte con ese nombre, cuenta con mi más absoluta discreción (CELA, Carta de 23/01/1959).

Ao problematizar a afirmação de Aub sobre a ausência de intenção provocativa ao enviar Homenaje - provocação que poderia envolver a habilidade e poder do editor ou a atenção da censura institucional ao texto -, longe de perseguir o que poderia haver de verdade ou mentira no comentário, interessa-nos destacar que a configuração da subjetividade na carta não se constrói de maneira restrita e como única expressão daquele que escreve. O diálogo epistolar está atravessado pelos interesses que motivam a participação de cada interlocutor, assim como acontece na vida social, sendo, portanto, um espaço que permite a encenação de papéis que constroem a empatia com o outro, como explica Marcos Antonio de Moraes (2001) ao analisar a correspondência de Mário de Andrade.

Aub dá mostra de transigência ao aceitar escrever o conto asséptico, assim, como deu mostras de transigência antes, autocensurando-se, ao enviar o primeiro texto para PSA. Na Fundación Max Aub, encontramos duas cartas elaboradas em dias seguidos, 28 e 29 de outubro de 1957, que anunciam o envio de obras diferentes, sendo que a

\footnotetext{
6 A carta que contém essa proposta foi escrita durante uma viagem de Aub ao Reino Unido, segundo o cabeçalho - The Old Rectory, Edmondthorpe, Melton Mowbray -, e só encontramos a versão manuscrita que está na Fundación Pública Gallega Camilo José Cela. Carta a Cela, 1 de janeiro de 1959.
}

escolha final foi pelo texto que representava o menor risco de ser barrado pela censura institucional. As mudanças de conteúdo observadas nas cartas acompanham esse movimento. Na primeira - a que não foi enviada, de acordo com os documentos arquivados na Fundación Pública Gallega Camilo José Cela - encontra-se a medida de seu temor de não conseguir a publicação ("Temo mucho"):

Las cosas que pasan: creí tener cien textos -por lo menos tres o cuatro cuentos- para sus 'Papeles'. Y resulta que, por una causa o por otra, no sirven. Le incluyo 'El prurito'. Temo mucho que no lo pueda publicar. Ojalá me equivoque.

Si no le sirve, dígamelo enseguida y le mandaré algún capítulo inofensivo de cualquiera de las dos novelas próximas (AUB, Carta de 28/10/1957).

Por sua vez, na segunda carta, a que efetivamente chegou ao destinatário, Aub se preocupa mais com o gosto e as expectativas do editor do que com a censura oficial: "Las cosas que pasan: creí tener, por lo menos, tres o cuatro cuentos para sus 'Papeles'. Resulta que por una causa o por otra, no sirven. Le incluyo un trozo de 'Las oposiciones’. Ojalá le guste” (AUB, Carta de 29/10/1957).

Cela levou alguns anos, e publicou cinco textos de Aub em PSA, para sugerir o envio de material passível de aprovação pela censura. Quando se trata de Américo Castro, essa sugestão acompanhou o primeiro convite de colaboração, em carta de 24 de maio de 1956: "por razones obvias, preferiría, claro es, que ese texto no fuese polémico sino científico. ¿Querrá usted enviarnos algo? Todo cabe en Papeles siendo suyo, y en esta casa usted manda" (CELA, 2009, p. 163). Cela justifica com argumentos históricos - o da ditadura sob a forma da expressão "por razones obvias" - seu zelo castrador, embora se contradiga ao expressar sua receptividade às colaborações de Castro - "Todo cabe en Papeles siendo suyo". Se o tom cuidadoso de seu discurso poderia também estar marcado por certa insegurança que é comum ao início de qualquer grande projeto, a contradição se amplia ao solicitar a um ensaísta envolvido em polêmicas antigas que escreva um texto incontroverso que, por sinal, associa a científico. A resposta é dada com as seguintes palavras:

Le agradezco muy de veras su cordial invitación, pero... me tracé hace años una línea de conducta, a costa de desgarros y dolores muy punzantes, y la línea sigue ahí, como una cicatriz bien marcada. [...] Ahora bien, a mi edad, $¡ 71$ !, hay que estar en donde se está. No acepto, ni colaboro con mi presencia a nada que huela a "comprensión". De ahí mi horror por cuanto hay tras la famosa cortinita (CELA, 2009, p. 164). 
Na mesma carta, no parágrafo seguinte, Castro dá um exemplo da ação censória institucional a sua produção que o leva ao ceticismo da resposta acima. No entanto, da mesma forma que Cela, mostra sinal de receptividade, ao demonstrar seu desejo de publicar no país e ao buscar signos de tolerância, que crescerá conforme receba e aprove os primeiros números de PSA, em outras palavras, quando passe a confiar nos êxitos editorias de seu interlocutor:

Un grupo de americanos -discípulos, amigos-cometió la imprudencia de querer imprimir un volumen con artículos y ensayos míos, puramente históricoliterarios, sin referencia a nada discutible. Pues bien, han puesto el veto a eso, sin razón ni motivo. Desde hace 20 años no he escrito nada para ser publicado ahí, me gustaría poder cambiar esa línea antes de terminar mi vida, pero no veo signos de tolerancia ni de comprensión (CELA, 2009, p. 164).

Poucos meses depois, na terceira carta do conjunto, é Castro quem volta a falar sobre colaboração para Papeles, ao enviar uma carta manuscrita - que, pelos poucos temas tratados e caráter resumido, mais parece um bilhete - da qual podemos inferir um pedido para que o convite para escrever em PSA permaneça ativo: "Su revista me agrada mucho, y confío en que alguna vez las circunstancias me permitan enviarle una colaboración en lugar de un cheque" (CELA, 2009, p. 165). De fato, não demorou para que a primeira colaboração fosse enviada, embora só tenha se realizado após uma visita de Castro a Cela em Maiorca, quando esteve na Espanha por motivo de saúde de sua mulher. Com frequência, desconfia de que as suas colaborações serão alteradas ou vetadas pela censura, da mesma forma que acontecera com o projeto de seus discípulos e amigos.

Vejamos as primeiras referências a esse desânimo de Castro ou à expectativa negativa quando se trata de submeter sua produção aos órgãos censores. Em carta de 25 de Julio de 1957, registra: "Si estoy con ganas de escribir, me gustaría intentar hacer algo sobre $L a$ Celestina, con destino a su revista, si logro hacer lo que deseo y si luego dejan publicarlo" (CELA, 2009, p. 169). Naquele momento, não consegue escrever sobre $L a$ Celestina, porém, durante a visita a Cela, disponibiliza duas colaborações para PSA. Enquanto espera a anuência da censura, Castro indica-nos uma estratégia oficial corrente de impedir a circulação de obras permitidas, como é o caso da limitação de divisas para a importação de livros. Encontramos na seguinte carta a Cela:

$\mathrm{Si}$, en contra de lo que espero, permitieran lo de "los Dioscuros", tendría que hacer mil sobretiros a mi costa, naturalmente. [...] Aunque la $[L a]$ Realidad histórica [de España] fue permitida, como no dejan divisas a los libreros para importarla, pues el resultado es como si estuviera prohibida. (CELA, 2009, p. 174)

Os textos enviados são Santiago y los Dioscuros e $L a$ orientalidad de los musulmanes de Al-Andalus, aprovados em sua integridade e publicados, respectivamente, nos número da revista de setembro e outubro de 1957. Cela aceita imprimir as 1000 separatas do texto, de acordo com o pedido de Castro, além das 50 distribuídas gratuitas como retribuição ao colaborador. No entanto, como o número de separatas pede autorização dos órgãos censores, parece mais adequado a Cela, em seu papel de editor, valer-se de certa manobra para evitar problemas, como a de não numerá-las. Confidencia a Castro:

Según la ley, los sobretiros se entienden no comerciales ni dispuestos para la venta, sino publicados como obsequio a los amigos o recuerdo a los admiradores. Un texto, por breve que fuera, destinado a la venta, requeriría nuevas y muy engorrosas censuras en las que, probablemente, nos iríamos a pique. Se lo digo con toda la cautela y discreción son pocas y pienso que no sería el mejor sistema el de encargar su reparto a ningún librero $[\ldots]$.

Como tampoco creo que nuestros beneméritos amigos de la censura entendiesen por sobretiros una edición de 1.000 ejemplares, creo que lo mejor sería que fuesen sin numerar. A la pregunta de que cuántos se hicieron podremos siempre responder con un vago 'muy pocos, cien o ciento veinte...' (CELA, 2009, p. 176).

Embora não tenhamos encontrado registros de que algum texto de Castro publicado em PSA haja sofrido interferência da censura, podemos resgatar exemplos de experiências negativas que o autor vivenciou em outras revistas ou editoras nas queixas contidas em suas cartas: "en una cosa publicada por Destino en Barcelona, la censura, en mi frase 'la dimensión imperativa de la persona', tacharon imperativa (tengo la foto)" (CELA, 2009, p. 413). A própria Alfaguara é acusada por Castro de administrar mal sua produção, mutilando-a, ao deixar de publicar sua entrevista, realizada por ocasião do ciclo de conferências organizado por Cela para divulgar a edição própria de Don Quijote (1967): "nunca me dijeron por qué no se publicó la entrevista que me hizo un Sr. Montini, en nombre de Alfaguara. ¿Fue detenida por quienes saben y pueden? Si silencio, para qué entrevista; si entrevista, por qué mutismo" (CELA, 2009, p. 469-470). Cela o convidara a apresentar uma das comunicações e se propõe a pagar - "en secreto" (CELA, 2009, p. 459) - por sua participação, mas Castro declina do convite devido a uma forma de conduta pessoal e profissional que zela pela coerência e devido à falta de liberdade de expressão na Espanha. 
Assim como acontece com Américo Castro, Rafael Alberti se preocupa constantemente com a possibilidade de ser censurado pelo histórico de obras mutiladas e o demonstra cada vez que envia uma colaboração. Temos um exemplo quando se trata do corte de poemas em livro a ser lançado pela editora Losada, embora não explique se houve censura institucional ou do editor, que Alberti emprega para generalizar as mutilações em suas obras: "La Editorial Losada publicará a fines de año mis Poesías Completas (o casi completas -siempre a mí me hacen mutilaciones-)" (CELA, 2009, p. 106). Outro exemplo, aproximadamente oito anos depois, ao enviar sonetos para a homenagem a Ramón Valle Inclán, expressa a Cela sua preocupação com os novos poemas: "Los he escrito, como ve, inmediatamente, recordando los maravillosos días que pasé con él en Roma hace ahora ¡31 años! Espero que la censura de ese hermoso país donde vive no se fije demasiado en el último soneto" (CELA, 2009, p. 141). Cela the transmite confiança ao responder: "La censura no se fijará en nada y, si lo hace, peor para ella" (CELA, 2009; 141).

Se não encontramos informações sobre mudanças solicitadas pela censura institucional a textos de Alberti publicados sob a responsabilidade de Cela, encontramos alterações sugeridas pelo escritor galego, em sua condição de editor, para adaptar-se às orientações oficiais. Segundo o modelo de Andrés de Blas, estamos diante de um caso de censura social. Em outra situação, Cela procura evitar que Alberti se autocensure. Exemplo do primeiro tipo de situação é a proposta de alteração da ficha biográfica de Alberti:

\footnotetext{
Me llega su ficha biográfica y me apoyo en su coletilla -“estaba ya hecha"- para hacerle un ruego: que me permita quitar, o pulir, sus alusiones políticas. A ningún puerto nos lleva que la censura se la cargue de la cruz a la fecha. Se trata, querido Alberti, de que su nombre (y tantos otros nombres) tome el aire de España, el confinado aire al que tanto bien puede hacer escuchar su poesía. Le hablo a usted con el corazón en la mano y mi intención, créame, no puede ser más honesta ni, probablemente, más pareja a la suya. Y más claro, el agua (CELA, 2009, p. 107).
}

Nessa ficha, Alberti havia organizado os principais acontecimentos de sua vida, praticamente ano por ano, entre 1902 e 1958, evidenciando, no período correspondente, sua participação a favor de grupos de esquerda, fosse por sua atuação política - em 1936, participa ativamente nas campanhas da coalizão de esquerda Frente Popular fosse por sua produção intelectual: "como secretario de la Alianza de Intelectuales Antifascistas trabaja mucho en la dirección de revistas, grupos teatrales para el frente, ediciones, etc" (CELA, 2009, p. 156).
Exemplo do segundo tipo de situação, em que o editor atua para evitar que o autor se autocensure, é a controvérsia sobre a inclusão do poema "Diálogo entre Venus y Príapo" no livro Poemas de amor, que Alberti preparava para ser publicado pela recém-nascida Alfaguara. Nesse diálogo, dois mitológicos seres representantes da fertilidade revelam seu amor e desejo mútuos por meio de expressivas imagens eróticas. Logo que o lê, Cela festeja o poema e aponta um risco: "Me llegan hoy el 'Diálogo entre Venus y Príapo' -cachondísimo, sí, pero no creo que insalvable en la censura" (CELA, 2009, p. 123). Vale a pena lembrar que o receio de Cela se sustenta devido aos parâmetros seguidos pela censura institucionalizada para permitir ou proibir uma obra, ou seja, a lista de perguntas que Manuel Abellán considera "un sencillo esquema inquisitório". Nos relatórios emitidos, deveria constar se a obra atacava alguns dos valores cultuados pelo Estado, como o regime franquista ou seus colaboradores, o dogma, a moral ou a Igreja ${ }^{7}$.

Inicialmente, Alberti decide incluir o poema, logo, repensa e opta por limitar suas ousadias: "He decidido no incluir en el libro el 'Diálogo de Venus y Príapo'. Haré algún nuevo poema más claro que ese, pero menos comprometedor" (CELA, 2009, p. 126). A solução da controvérsia se produz com a intervenção de Cela ao motivá-lo a tentar a inclusão: "Es lástima que no quiera incluir el 'Diálogo de Venus y Príapo' pero, en fin, usted es quien tiene la palabra" (CELA, 2009, p. 141). A pesar de demorar mais do que a paciência de Alberti gostaria, dois anos, o livro é publicado em 1967, sem que constem mutilações segundo os materiais que examinamos, e em duas coleções: a de luxo e com pequena tirada pela "Gallo en la torre" e a para um público mais amplo, com 1000 exemplares numerados, pela Amans Amens, que reunia livros de poesia de poetas como Alberti, Miguel Hernández e Vicente Aleixandre, com ilustrações feitas com a técnica da ponta seca. Ambas as coleções contam com o material visual criado por Alberti, sendo que a primeira gerou diferentes versões do material completo - praticamente personalizadas -, conforme consta nas informações pós-textuais. No total, foram distribuídos mil e sessenta e quatro exemplares (ALBERTI, 1967).

Tamanho empenho em indicar a história da composição e impressão do livro por parte de Alfaguara, naturalmente, remete-nos à estratégia que Cela havia usado antes para que o livro de Castro, Santiago y los Dioscuros, escapasse da censura, isto é, a de editar apenas 1000 exemplares, daquela vez, sem numerá-los. Por outro

\footnotetext{
A lista completa é: “1) ¿Ataca al dogma?, 2) ¿a la moral?, 3) ¿a la Iglesia o a sus ministros?,4) ¿al régimen y a sus instituciones?, 5) ¿a las personas que colaboran o han colaborado con el régimen?, 6) los pasajes censurables, ¿califican el contenido total de la obra?, y 7) informe y otras observaciones" (ABELLÁN, 1980, p. 19).
} 
lado, sugere-nos uma opção editorial pela edição de luxo e pequeno número de exemplares - por sinal, ambas são coleções de luxo, levando-se em conta o contexto social -, baseada no alcance da censura como instituição que também incidia sobre o mercado de livros ao dificultar sua divulgação de diversas formas ${ }^{8}$.

As duas situações experimentadas por Alberti permitem-nos supor que, mesmo diante da disposição para fazer história com a publicação de textos dos escritores exilados, o comportamento de Cela como editor indica que ele próprio havia estabelecido certa gradação de dificuldades ao lidar com a censura, sendo que conseguir publicar um texto com referências a questões políticas era mais difícil que um texto com referências a questões sexuais.

Ainda sobre a autocensura, são poucos também os casos desse exercício encontrados na correspondência de Américo Castro, se consideramos a quantidade de missivas trocadas e de textos publicados em PSA. O primeiro deles surge quando se trata de Prioridad de entender, que saiu no número de abril de 1958 de Papeles, considerando o que pede ao editor ou o possível esforço que pressupõe escrever vigiando-se para que não haja nenhuma frase considerada ofensiva. Castro se propõe a atenuar o texto para evitar problemas e escreve: "P.D. No creo quede en mi texto ninguna frase de tono violento. Pero si así fuera, le ruego que la atenúe. Deseo atenerme a lo de "poignée de fer, gant de velours'. Me conviene a mí y a la revista" (CELA, 2009, p. 207). Em outro caso, diz a Cela: "le mandaré mi artículo sobre Las Casas, suavizando alguna frase gruesa del final; aun así, no sé si la censura teológica lo dejará pasar" (CELA, 2009, p.429). A resposta de Cela não poderia ser mais alentadora ao estabelecer uma aliança entre autor, editor e editora quando se trata de ultrapassar os obstáculos da censura, sendo ele próprio um representante desses três grupos:

Lo que usted haga, bien hecho estará; pero yo en su pellejo no suavizaría el final del "Las Casas" por temor a la intervención de la censura teológica (?). La censura, mi querido don Américo, es una muleta de primer orden para quienes -autores, editores o comentaristas- no quieren dar la raca (sic). Que no es el caso de usted, ni el mío, ni el de la editorial (CELA, 2009, p. 430).

Castro e Alberti são os escritores que mais verbalizaram - ao longo das respectivas correspondências - a preocupação em ter seu texto interditado pelas vias

\footnotetext{
8 Conforme esclarece Andrés de Blas (1999, p. 290), a censura como instituição incidia sobre o mercado de livros "autorizando un texto en tirada limitada o autorizándolo sólo en una edición de lujo, o prohibiendo su exhibición en los escaparates de las librerías, aspectos todos ellos que dificultarán la difusión del producto".
}

institucionais. Em comparação, Max Aub é o autor que efetivamente teve mais problemas com a censura, se consideramos as suas variadas formas, segundo o que aparece nas cartas que compõem o nosso corpus. Além do texto que discutimos antes, Homenaje a los que nos han seguido, Aub é protagonista de uma história curiosa e que não consta em sua correspondência com Cela. Aliás, existe um complexo silêncio entre os correspondentes de 1966 a 1970, embora não tenha afetado a circulação de textos do escritor exilado em Papeles. Aub conta a Jorge Guillén que o homenageara em um poema a ser publicado na revista. Quando Guillén pergunta a Cela sobre este poema, fica sabendo que:

Los versos en que Max Aub canta a los amigos ['Nosotros, entonces'] los tengo un poco parados. A Dalí le llama hijo de puta, epíteto quizá excesivo; se lo consulté al interesado, por eso de que los surrealistas son incoercibles y todavía no he tenido respuesta. Publicarlo, sin más ni más, me parecería más bien poco discreto (CELA, 2009, p. 599).

$\mathrm{Na}$ resposta de Cela, vê-se que sua atuação censória ao adiar a publicação do texto não está determinada pelos critérios estabelecidos pela censura institucionalizada. Com efeito, parece responder a suas convicções de editor e a sua preocupação em evitar conflitos. Guillén (CELA, 2009, p.599) faz uma sugestão que acaba solucionando o impasse: a de que se mude o "hijo de puta" por "hijo de ruta". Sabemos da mudança pela aparição do poema em PSA com a troca do verso, sem que autor e editor a tivessem comentado.

Apesar de ter assumido contornos próprios em certos momentos históricos pela necessidade de adequação às mudanças na sociedade e de sobrevivência do regime, alguns críticos concordam em que não houve avanços significativos na legislação da censura para a publicação de livros desde a lei promulgada durante a guerra em 1938 até sua substituição por outra com elementos aberturistas em 1966, conhecida como a "Ley Fraga", devido ao nome do ministro de Informação e Turismo da época, Manuel Fraga Iribarne. Talvez a diferença mais marcante esteja no procedimento de autorização de textos, com o fim da censura prévia a que estava submetida toda obra em projeto, ou seja, antes de sua publicação, segundo a exigência da lei de 38. Por outro lado, a lei de 66 criou a fórmula da consulta voluntária que dava ao editor ou autor a opção de apresentar a obra aos censores antes da publicação para que recebesse sua aprovação, recusa ou uma lista de aspectos que deveriam ser modificados. Essa concessão tinha como contrapartida as pesadas multas e sanções que insidiam sobre os editores e as obras divulgadas que fossem consideradas impróprias. 
Tantos anos de vivência sob o signo da censura levaram os escritores e editores a procurar desde formas linguísticas até formas organizacionais e administrativas de lidar com ela. Algumas dessas estratégias identificamos na discussão entre Cela e os seus interlocutores, sendo que talvez a principal delas resida na própria figura de Cela em seu papel de cônsul - como insiste em apresentar-se aos seus interlocutores do exílio -, dado que implica em que esteve do lado franquista, era respeitado como escritor pelo regime e pessoalmente bem relacionado com membros do grupo no poder, além de conhecer os mecanismos de funcionamento da censura, pois exerceu oficialmente essa atividade entre 1941 e 1945. Estavam dadas, portanto, as condições, ao menos mínimas, para que Cela atuasse como "muro de contenção" - expressão de Jordi Gracia (2006, p. 302) para referir-se à importância de Cela para PSA - para a publicação dos escritores exilados ou fosse capaz de dar o respaldo que comenta Castro, em sua última missiva, para fazer circular ideias polêmicas ou inovadoras:

No sé si el volumen de Taurus se agotará en vida mía. Tampoco sé si algunos de mis grandes amigos $-\mathrm{Ud}$. en primera fila- querrían añadir una página a fin de respaldar con su prestigio la idea de que 'lo español' necesita ser concebido, utilizado y protegido en forma distinta a como lo hace la R. Academia de la Historia (CELA, 2009, p. 482).

Entre as várias imagens de Cela que podem surgir do estudo da monumental correspondência arquivada na fundação que leva o seu nome, uma delas está dada pelo nosso corpus que indica o projeto de publicar textos dos exilados na península, resguardando a obra dos exilados e a sua própria e inscrevendo-se como um relevante mediador cultural nos anos 50 e 60 .

\section{Referências}

\section{FUNDACIÓN MAX AUB.}

FUNDACIÓN PÚBLICA GALLEGA CAMILO JOSÉ CELA.

ABELLÁN, Manuel L. Censura y creación literaria en España (1939-1976). Barcelona: Ediciones Península, 1980.
ALBERTI, Rafael. Poemas de amor. Madrid: Alfaguara, 1967.

ANDRÉS DE BLAS, José. El libro y la censura durante el franquismo: Un estado de la cuestión y otras consideraciones. Espacio, Tiempo y Forma. Historia Contemporánea, Madrid, n. 12, p. 281-301, 1999.

ANDRÉS DE BLAS, José. La censura de libros durante la Guerra Civil Española. In: RUIZ BAUTISTA, Eduardo (Coord.). Tiempo de censura. La represión editorial durante el franquismo. Gijón: Ediciones Trea, 2008. p. 19-20.

AUB, Max. Homenaje a los que nos han seguido. Revista de la Universidad de México, México, DF, n. 3, p. 17, nov. 1962. Disponível em: $<\mathrm{http} / /$ www.revistadelauniversidad.unam.mx/ ojs_rum/index.php/rum/article/view/8094/9332>. Acesso em: 08 nov. 2014.

AUB, Max. Nosotros, entonces. Papeles de Son Armadans. Madrid, Palma de Mallorca, año XIV, tomo LII, n. CLV, p. 151-157, feb. 1969.

CELA, Camilo José. Correspondencia con el exilio. Barcelona: Destino, 2009.

CELA CONDE, Camilo José. Cela, mi padre. Madrid: Ediciones Temas de Hoy, 1989.

DE MARCO, Valeria. O cru e o polido nas cartas dos exilados republicanos espanhóis. In: WAIZBORT, Leopoldo (Org.). A ousadia crítica: ensaios para Gabriel Cohn. Rio de Janeiro: Beco do Azougue, 2008. p. 285-302.

GRACIA, Jordi. Estado y cultura. El despertar de una conciencia crítica bajo el franquismo, 1940-1962. Barcelona: Editorial Anagrama, 2006.

LARRAZ, Fernando. Letricidio español. Censura y novela durante el franquismo. Gijón: Ediciones Trea, 2014.

MONTEJO GURRUCHAGA, Lucía. Las limitaciones de expresión en España durante las décadas cincuenta y sesenta: el ejemplo de dos antologías poéticas. Epos: Revista de Filología, Madrid, n. 12, p. 277-295, 1996.

MORAES, Marcos Antonio de. $O$ orgulho de jamais aconselhar: a epistolografia de Mário de Andrade. São Paulo: Edusp/Fapesp, 2007.

SIRINELLI, Jean-François. Os intelectuais. In: REMOND, René (Org.). Por uma história política. Rio de Janeiro: FGV, 2003. p. 231-269.

Recebido: $15 / 10 / 2015$

Aprovado: 22/11/2015

Contato: solangemunhoz@yahoo.com.br 